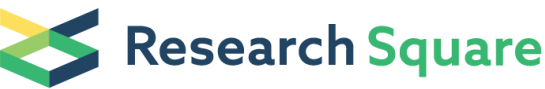 \\ Preprints are preliminary reports that have not undergone peer review. \\ They should not be considered conclusive, used to inform clinical practice, \\ or referenced by the media as validated information.
}

\section{Respiratory physiology of COVID-19 and Influenza associated Acute Respiratory Distress Syndrome}

\section{Niklas Kronibus}

Saarland University Medical Center and Saarland University Faculty of Medicine: Universitatsklinikum des Saarlandes und Medizinische Fakultat der Universitat des Saarlandes

\section{Frederik Seiler}

Saarland University Medical Center and Saarland University Faculty of Medicine: Universitatsklinikum des Saarlandes und Medizinische Fakultat der Universitat des Saarlandes

\section{Guy Danziger}

Saarland University Medical Center and Saarland University Faculty of Medicine: Universitatsklinikum des Saarlandes und Medizinische Fakultat der Universitat des Saarlandes

\section{Ralf M. Muellenbach}

Kassel Hospital: Klinikum Kassel GmbH

\section{Christian Reyher}

Kassel Hospital: Klinikum Kassel GmbH

\section{André Becker}

Saarland University Medical Center and Saarland University Faculty of Medicine: Universitatsklinikum des Saarlandes und Medizinische Fakultat der Universitat des Saarlandes

\section{Maren Kamphorst}

Saarland University Medical Center and Saarland University Faculty of Medicine: Universitatsklinikum des Saarlandes und Medizinische Fakultat der Universitat des Saarlandes

\section{Torben Rixecker}

Saarland University Medical Center and Saarland University Faculty of Medicine: Universitatsklinikum des Saarlandes und Medizinische Fakultat der Universitat des Saarlandes

\section{Carlos Metz}

Saarland University Medical Center and Saarland University Faculty of Medicine: Universitatsklinikum des Saarlandes und Medizinische Fakultat der Universitat des Saarlandes

\section{Philipp M. Lepper ( $\square$ philipp.lepper@uks.eu )}

Universitatsklinikum des Saarlandes und Medizinische Fakultat der Universitat des Saarlandes https://orcid.org/0000-0003-3620-0912

\section{Robert Bals}

Saarland University Medical Center and Saarland University Faculty of Medicine: Universitatsklinikum des Saarlandes und Medizinische Fakultat der Universitat des Saarlandes

\section{Sebastian Mang}


Saarland University Medical Center and Saarland University Faculty of Medicine: Universitatsklinikum des Saarlandes und Medizinische Fakultat der Universitat des Saarlandes

\section{Research}

Keywords: Coronavirus-disease 2019 (COVID-19), Acute Respiratory Distress Syndrome (ARDS), mechanical ventilation, Influenza A / B, extracorporeal membrane oxygenation (ECMO)

Posted Date: May 13th, 2021

DOl: https://doi.org/10.21203/rs.3.rs-505368/v1

License: (c) (i) This work is licensed under a Creative Commons Attribution 4.0 International License. Read Full License 


\section{Abstract}

Background: There is ongoing debate whether lung physiology of COVID-19 associated acute respiratory distress syndrome (ARDS) differs from ARDS of other origin.

Objective: The aim of this study was to analyze and compare how critically ill patients with COVID-19 and Influenza A or B were ventilated in our tertiary care center with or without extracorporeal membrane oxygenation (ECMO). We ask if acute lung failure due to COVID-19 requires different intensive care management compared to conventional ARDS.

Methods: 25 patients with COVID-19 associated ARDS were matched to a cohort of 25 Influenza patients treated in our center from 2011 to 2021. Subgroup analysis addressed whether patients on ECMO received different mechanical ventilation than patients without extracorporeal support.

Results: Compared to Influenza-associated ARDS, COVID-19 patients had higher ventilatory system compliance (40.7 ml/mbar [31.8 - $46.7 \mathrm{ml} / \mathrm{mbar}]$ vs. $31.4 \mathrm{ml} / \mathrm{mbar}[13.7-42.8 \mathrm{ml} / \mathrm{mbar}], \mathrm{p}=0.198)$, higher ventilatory ratio $(1.57$ [1.31 - 1.84] vs. 0.91 [0.44 - 1.38], $p=0.006)$ and higher minute ventilation at the time of intubation (mean minute ventilation $10.7 \mathrm{I} / \mathrm{min}[7.2-12.2 \mathrm{l} / \mathrm{min}]$ for COVID-19 vs. $6.0 \mathrm{l} / \mathrm{min}$ [2.5 - $10.1 \mathrm{l} / \mathrm{min}$ f for Influenza, $p=0.013$ ). There were no measurable differences in $\mathrm{P} / \mathrm{F}$ ratio, positive end-expiratory pressure (PEEP) and driving pressures $(\triangle P)$. Respiratory system compliance deteriorated considerably in COVID-19 patients on ECMO during 2 weeks of mechanical ventilation $\left(\mathrm{C}_{\mathrm{rs}}\right.$, mean decrease over 2 weeks $-23.87 \mathrm{ml} / \mathrm{mbar} \pm 32.94 \mathrm{ml} / \mathrm{mbar}, p=0.037$ ), but not in ventilated Influenza patients on ECMO and less so in ventilated COVID-19 patients without ECMO. For COVID-19 patients, low driving pressures on ECMO were strongly correlated to a decline in compliance after 2 weeks (Pearson's R $0.80, p=0.058)$. Overall mortality was insignificantly lower for COVID-19 patients compared to Influenza patients ( $40 \%$ vs. $48 \%, p=0.31)$. Outcome was insignificantly worse for patients requiring veno-venous ECMO in both groups ( $50 \%$ mortality for COVID-19 on ECMO vs. $27 \%$ without ECMO, $p=0.30 / 56 \%$ vs $34 \%$ mortality for Influenza A/B with and without ECMO, $p=0.31$ )

Conclusion: The pathophysiology of early COVID-19-associated ARDS differs from Influenza-associated acute lung failure by sustained respiratory mechanics during the early phase of ventilation. We question whether intubated COVID-19 patients on ECMO benefit from extremely low driving pressures, as this appears to accelerate derecruitment and consecutive loss of ventilatory system compliance.

\section{Background}

The emergence of COVID-19 in December 2019 brought a surge of patients with viral pneumonia and associated acute respiratory distress syndrome (ARDS) $)^{1,2}$ Shortly into the first pandemic wave, observations arose that respiratory failure due to COVID-19 could have unusual physiologic features ${ }^{3-6}$. In Mai 2020, Marini et al. described that patients with COVID-19 often present with severe hypoxemia yet only mildly impaired respiratory mechanics ${ }^{7}$. Since ARDS was historically accompanied by a loss of 
functional residual capacity and compliance ${ }^{8}$, this observation sparked a debate whether respiratory failure due to COVID-19 might be a different disease. To this day, this question has not yet been sufficiently answered. Another recurrent observation in COVID-19 is a disproportionate increase in respiratory effort ${ }^{9}$, visible through elevated minute ventilation, leading to only marginal clearance of carbon dioxide $\left(\mathrm{CO}_{2}\right)$. Several mechanisms have been suggested to account for this discrepancy, e.g. ventilation-perfusion mismatch with increased functional right-to-left shunting ${ }^{10}$, increased $\mathrm{CO}_{2}$ production ${ }^{11}$ or a combination of both. The question if COVID-19 associated ARDS is different from 'classic' ARDS is not only of academic purpose, as it might imply a need for different intensive care management ${ }^{12-14}$.

Early in the first COVID-19 pandemic wave, centers started to employ extracorporeal membrane oxygenation for most severe COVID-19 cases, drawing on existing cohort data on ECMO for ARDS of different origin ${ }^{15,16}$. While ECMO has proven to reduce mortality of patients with very severe COVID-1917, the mortality benefit for these patients was unsatisfyingly low ${ }^{18}$. It is well accepted that high driving pressures may increase mortality of ARDS patients through ventilator-associated lung injury (VILI) ${ }^{19}$. Consequently, these patients usually receive high positive end-exspiratory pressure (PEEP) and low driving pressures at the cost of $\mathrm{CO}_{2}$ elimination to limit mechanical power on the lungs ${ }^{20}$. The strength of ECMO for ARDS patients is considered not only providing oxygenation but allowing protective ventilation through effective extracorporeal $\mathrm{CO}_{2}$ clearance. If ventilator-induced lung injury contributes to disease progression in COVID-19, then protective ventilation during ECMO should decelerate the deterioration of lung mechanics.

We therefore aimed to check whether COVID-19 patients on ECMO benefitted from low driving pressures. Hence, we analyze in detail how intubated COVID-19 patients were ventilated on our ward in comparison to patients with Influenza-associated ARDS. Furthermore, we checked whether ventilation with high PEEP and low driving pressures during ECMO for COVID-19 had a positive impact on respiratory system physiology and compliance and compared these data to the Influenza cohort.

\section{Methods}

\section{Study design}

Our ICU is a tertiary care unit with 24 beds dedicated to the treatment of COVID-19 patients. Most COVID19 patients included in the study were intubated in primary or secondary care centers nearby and then transferred for evaluation of ECMO. Several patients were cannulated externally by our mobile ECMO teams and then transferred to Homburg on running ECMO. We first analyzed basic characteristics of 25 patients with COVID-19, treated in our center from March 2020 to March 2021. All included patients were mechanically ventilated and devoid of severe comorbidities. Patients aged between 18 and 70 with laboratory-confirmed SARS-CoV-2 infection, defined as a positive result on real-time RT-PCR assay from nasal or pharyngeal swabs or respiratory tract aspirates, with hypoxemia and a high respiratory drive 
meeting the criteria for moderate ARDS according to the Berlin definition of ARDS were included in this cohort.

Most COVID-19 patients treated in our center could not be recruited for the study cohort due to one of the following exclusion criteria: age- or comorbidity-related contraindication for extracorporeal life support, additional circulatory failure, defined as requiring intravenous noradrenaline of more than $0.3 \mu \mathrm{g} / \mathrm{kg} / \mathrm{min}$, cardiopulmonary resuscitation prior to intubation for COVID-19-associated ARDS, mechanical ventilation for COVID-19 for more than 8 days prior to study inclusion.

14 patients from the COVID-19 cohort later received veno-venous extracorporeal membrane oxygenation due to respiratory failure.

A matched control cohort of 25 patients with ARDS due to Influenza A or B, treated in our center from 2011 to 2021, was then recruited for comparison. As severe COVID-19 affects predominantly men, matching both cohorts for sex was not possible. Instead, both groups were matched according to age and $\mathrm{BMI}$ as well as possible. The same exclusion criteria were applied for the recruitment of Influenza patients.

We compared the following parameters taken from day 1, 2, 4, 8 and 16 of invasive ventilation: positive end-expiratory pressure (PEEP), plateau pressure (PP), driving pressure $(\triangle \mathrm{P})$ and Respiratory Rate (RR).

Ventilation was in pressure-controlled mode in all patients. Generally, we targeted a protective ventilation approach, aiming at driving pressures below $15 \mathrm{cmH}_{2} \mathrm{O}$ and tidal volumes (VT) of approximately $6 \mathrm{ml}$ per $\mathrm{kg}$ of predicted bodyweight (PBW). The mean arterial pressure target was $60-65 \mathrm{mmHg}$ if physiological aims were reached. These included capillary refill time (i.e. warm periphery), sufficient urinary output ( $\geq$ $0.5 \mathrm{ml} / \mathrm{kg} / \mathrm{h}$ ) and normal lactate levels $(\leq 2.0 \mathrm{mmol} / \mathrm{l})$. Norepinephrine was the vasopressor of choice in patients with $\mathrm{pH} \geq 7.25$. Inotrope use was initiated if $\mathrm{ScvO}_{2}$ was below $65 \%$ despite adequate hemoglobin levels. Nutrition in both groups was done according to the same standards.

If patients were not deeply sedated and breathed spontaneously, the actual rate of assisted spontaneous breathing was counted whenever intended and actual respiratory rates diverged by more than 2 per minute.

Derived from the above-mentioned parameters as well as results from blood gas samples, we calculated the following parameters: $\mathrm{P}_{\mathrm{a}} \mathrm{O}_{2} / \mathrm{F}_{\mathrm{i}} \mathrm{O}_{2}$ ratio (arterial oxygen partial pressure divided by inspiratory oxygen fraction), ventilatory system compliance, both absolute and in relation to idealized body weight (tidal volume in relation to predicted body weight divided by driving pressure), ventilatory ratio (VR) as a measure of ventilator efficiency, calculated as $\left(\mathrm{VE}_{\text {real }} \times \mathrm{PaCO}_{2 \text { real }}\right)$ divided by $(100 \mathrm{~mL} / \mathrm{min} \times$ predicted body weight $(\mathrm{PBW} ; \mathrm{kg}) \times 40 \mathrm{mmHg}\left(\right.$ expected $\left.\mathrm{PaCO}_{2}\right)$ ).

We defined the primary endpoint 'death from any cause' to calculate 28-day and 60-day mortality for both cohorts and subgroups as well as the secondary endpoint 'free from ventilator support after 15 days of 
ventilation' to compare weaning success in both groups.

\section{Statistical analysis}

Continuous variables are displayed as mean, standard deviation and $95 \%$ confidence intervals. For ordinal variables and non-normally distributed continuous variables, we calculated median and interquartile range.

Horizontal comparisons between groups were done by two-sided t-testing for normally distributed continuous variables and Man-Whitney-U-test for non-continuous parameters. Changes in parameters over time were analyzed by paired two-sided t-testing at a significance level of 0.05 . Kaplan-Meier-curves were plotted using the corresponding SPSS tool with 'death from any cause' as counted event. We performed log rank tests to compare survival between groups. Analysis and plotting were performed with SPSS Statistics v. 2.6.0.0.

\section{Results}

\section{I) Basic patient characteristics}

Basic patient characteristics are displayed in Table I. As severe COVID-19 affects predominantly men, the COVID-19 group has an excess of male patients (20 of 25 (80\%) vs. 16 of $25(64 \%)$. Apart from a nonsignificant age difference $(61,7$ years [ $53,1-68,1$ years] for COVID-19 vs. 55,7 years [45,5-65,4 years] for Influenza, $p=0.08$ ), both groups were well comparable regarding height, weight, body-mass index (BMI) and oxygenation impairment at the beginning of invasive ventilation.

Most frequent comorbidities were adiposity, arterial hypertension, Diabetes mellitus and coronary heart disease.

Both groups showed severe hypoxemia at the time of intubation. Mean arterial oxygen partial pressure before intubation was slightly higher in the influenza group (COVID19: paO2 $84.4 \mathrm{mmHg}[76.8$ - 92.1 $\mathrm{mmHg}]$ vs. $93.3 \mathrm{mmHg}[71.8-114.8 \mathrm{mmHg}]$ for Influenza, $\mathrm{p}=0.31)$. Prior to intubation, patients received either oxygen supplementation via high-flow nasal cannula or non-invasive ventilation. Mean inspiratory oxygen fraction during non-invasive oxygenation was slightly lower in the COVID-19 group (0.6 [0.49$0.70], n=14)$ compared to control $(0.75[0.53-0.84], n=9]$.

13 of 25 COVID-19 patients (42\%) and 16 of 25 Influenza (64\%) patients received veno-venous extracorporeal membrane oxygenation for respiratory failure few days after intubation.

\section{II) Horizontal comparison of ventilation parameters}

On the first day of invasive ventilation, there were no significant differences in $\mathrm{P} / \mathrm{F}$ ratio $(127.9 \mathrm{mmHg}$ [112.8 - $161.3 \mathrm{mmHg}$ ] for COVID-19 vs. $135.4 \mathrm{mmHg}[100.3$ - 180.4] $\mathrm{mmHg}, p=0.56$ ), positive endexspiratory pressure (12.0 mbar [9.6 - $13.5 \mathrm{mbar}$ for COVID-19 vs. $13.0 \mathrm{mbar}[9.0-15.5 \mathrm{mbar}$ for 
Influenza, $p=0.37$ ), plateau pressure (23.5 mbar [20.8 - 29.0 mbar] for COVID-19 vs. 25.0 mbar [24.0 $28.5 \mathrm{mbar}$ for Influenza, $p=0.56$ ) or driving pressure (13.5 mbar [10.8 - $16.0 \mathrm{mbar}$ for COVID-19 vs. 12.0 mbar [11.0 - $14.5 \mathrm{mbar}]$ for Influenza, $\mathrm{p}=0.64$ ) between both groups.

Similar ventilation pressures produced higher tidal volumes in relation to predicted body weight in COVID19 patients $(7.69 \mathrm{ml} / \mathrm{kgBW}[7.12-8.12 \mathrm{ml} / \mathrm{kgBW})$ compared to control $(5.12 \mathrm{ml} / \mathrm{kgBW}[3.14-8.40$ $\mathrm{ml} / \mathrm{kgBW}], p=0.06)$, indicating less impaired ventilatory system compliance in the COVID-19 group. COVID-19 patients required significantly higher ventilation frequencies $\left(20.0 \mathrm{~min}^{-1}\left[15.5-21.3 \mathrm{~min}^{-1}\right] \mathrm{vs}\right.$. $\left.14.0 \mathrm{~min}^{-1}\left[12.5-17.5 \mathrm{~min}^{-1}\right], p=0.011\right)$ and minute ventilation $(10.7 \mathrm{l} / \mathrm{min}[7.2-12.2 \mathrm{l} / \mathrm{min}] \mathrm{vs} .6 .0$ $\mathrm{I} / \mathrm{min}[2.5-10.1 \mathrm{l} / \mathrm{min}], p=0.013)$ for sufficient CO2 elimination. Indeed, calculated static compliance of the respiratory system was higher in COVID-19 patients than Influenza patients $(40.7 \mathrm{ml} / \mathrm{mbar}[31.8-$ $46.7 \mathrm{ml} / \mathrm{mbar}$ vs. $31.4 \mathrm{ml} / \mathrm{mbar}$ [13.7 $-42.8 \mathrm{ml} / \mathrm{mbar}$, $\mathrm{p}=0.198$ ) throughout the observation period. We calculated ventilatory ratio (VR) for both groups to assess ventilation efficacy. VR was significantly higher in the COVID-19 cohort (1.57 [1.31 - 1.84] vs. 0.91 [0.44 - 1.38], $p=0.006)$. For a comprehensive overview of ventilation parameters, s. Tables II, III and Figure I.

\section{III) Longitudinal comparison of ventilation parameters}

Immediately after intubation, most patients in both groups received pressure-controlled ventilation (PCV) during deep sedation or relaxation. The proportion of patients with strictly controlled ventilation on the first day was $79 \%$ in the COVID-19 group (11/14) and 100\% in the Influenza group (9/9). All patients for whom ventilation data from the first day of mechanical ventilation were missing could not be included into the analysis.

As ventilation progressed, an increasing number of patients could be weaned to augmented spontaneous breathing (ASB) with continuous positive airway pressure (CPAP). On day $8,41 \%$ of COVID-19 patients and $38 \%$ of Influenza patients breathed spontaneously with pressure support. On day 16 , the rate of patients still on controlled ventilation had dropped to $9.5 \%$ in the COVID-19 group (2/21) but stayed relatively unchanged at $36 \%(4 / 11)$ in the control group.

Except for few Influenza patients developing prolonged disease, we observed that COVID-19 patients were ventilated much longer than most Influenza patients. Odds Ratio in the overall cohort for breathing free from ventilator 15 days after intubation was 3.5 for Influenza compared to COVID-19.

To assess how ventilatory system compliance developed over time, we performed longitudinal pair-wise ttest comparisons of the initial compliance from the day of intubation to day 8 and day 16 of invasive ventilation.

We detected a continuous decrease of compliance in the COVID-19 cohort, with a significant reduction after 2 weeks of ventilation $(47.99 \mathrm{ml} / \mathrm{mbar} \pm 32.80 \mathrm{ml} / \mathrm{mbar} v \mathrm{~s} .24 .13 \mathrm{ml} / \mathrm{mbar} \pm 10.70 \mathrm{ml} / \mathrm{mbar}$, mean difference after 15 days being $-23.87 \mathrm{ml} / \mathrm{mbar} \pm 32.94 \mathrm{ml} / \mathrm{mbar}, p=0.037$ ) (Figure II). In contrast, ventilatory system compliance improved in the Influenza cohort after 7 days $(28.32 \mathrm{ml} / \mathrm{mbar} \pm 21.98$ 
$\mathrm{ml} / \mathrm{mbar} v s .34 .85 \mathrm{ml} / \mathrm{mbar} \pm 29.59 \mathrm{ml} / \mathrm{mbar}, p=0.10$ ). Since the course of ARDS tended to be much shorter for Influenza patients, we cannot provide a comparison in this cohort over 15 days, as only 2 patients would have qualified for pair-wise comparison between day 1 and 16 .

\section{IV) Subgroup analysis - ECMO vs. Non-ECMO}

Gradual decline in compliance was particularly present in the subgroup of COVID-19 patients receiving extracorporeal support (mean loss of compliance after 7 days $19.5 \mathrm{ml} / \mathrm{mbar} \pm 42.6 \mathrm{ml} / \mathrm{mbar}, p=0.31$, mean loss after 15 days: $-36.19 \mathrm{ml} / \mathrm{mbar} \pm 41.88 \mathrm{ml} / \mathrm{mbar}, p=0.09)$. COVID-19 patients not on ECMO also deteriorated in compliance, however, the loss of compliance was not as strong $(-9.08 \mathrm{ml} / \mathrm{mbar} \pm 4.43$ $\mathrm{ml} / \mathrm{mbar}$ after 15 days, $p=0.010$ ).

After ECMO was initiated in most patients, we checked whether ventilation strategies changed following ECMO initiation. Indeed, for the COVID-19 group, patients on ECMO received significantly higher PEEP on day 8 and 16 compared to patients without ECMO (Day 8: 12.5 mbar \pm 2.5 mbar vs. 10.3 mbar \pm 2.0 mbar, $p=0.025$, Day 16: 12.3 mbar \pm 2.3 vs. 7.8 mbar \pm 1.8 mbar, $p<0.001)$. Attempting to limit VILI, patients on ECMO were ventilated with lower driving pressures. This difference was small for day 8 , as not all patients had been cannulated up to that day but was significant for day 16 (Day 8: $13.8 \mathrm{mbar} \pm 4.6$ vs. $14.2 \mathrm{mbar} \pm 2.6 \mathrm{mbar}, \mathrm{p}=0.83$, Day $16: 11.3 \mathrm{mbar} \pm 2.3 \mathrm{mbar}$ vs. $16.6 \mathrm{mbar} \pm 4.5 \mathrm{mbar}, \mathrm{p}=0.002$ )

In contrast, there were no differences between PEEP and driving pressures between patients with and without ECMO for the Influenza group (not shown).

Since patients on ECMO tended to receive lower driving pressures but also seemed to deteriorate in ventilatory system compliance over time, we checked for correlations between a reduction in driving pressure and decreases in compliance over 15 days. We found that decreased driving pressures as a strategy of protective ventilation on ECMO was positively correlated to a loss of compliance after 15 days in bivariate correlation analysis (Pearson's $\mathrm{R}=0.80, \mathrm{p}=0.058$ ) in the COVID-19 group. In contrast, COVID19 patients not receiving ECMO showed an inverse correlation between change in driving pressure and compliance on day 16 (Pearson's $\mathrm{R}=-0.92, \mathrm{p}=0.025$ ). Compared to the COVID-19 group, this correlation was weak for Influenza patients on ECMO between the first and eighth day of ventilation (Pearsoncoefficient $-0.10, p=0.88$ ).

\section{IV) Outcome}

We determined 'death from any cause' as an endpoint to assess survival rates after 28 and 60 days from the beginning of invasive ventilation.

28-day mortality was $16 \%$ for the COVID-19 group compared to $36 \%$ in the control group. As KaplanMeier-plots demonstrate (s. Figure III A to C), overall survival was slightly better for the COVID-19 group compared to control ( $40 \%$ vs. $48 \%$ for Influenza, $p=0.31)$. Requiring veno-venous ECMO was a negative predictive factor for survival in both groups ( $50 \%$ mortality for COVID- 19 on ECMO vs. $27 \%$ without ECMO, $p=0.30 / 56 \%$ vs $34 \%$ mortality for Influenza A/B with and without ECMO, $p=0.31$ ). 


\section{Discussion}

Our study provides evidence that, during the early phase of mechanical ventilation, COVID-19 associated ARDS differs from Influenza-associated ARDS, mainly in lung mechanics. The ventilator ratio in patients with COVID-19 associated ARDS is statistically significant higher than in patients with Influenzaassociated ARDS. Thus, the efficacy of $\mathrm{CO}_{2}$ elimination in COVID-19 associated ARDS is highly impaired.

The finding that COVID-19 patients present with higher minute ventilation to achieve similar $\mathrm{CO}_{2}$ clearance is in line with results from other groups ${ }^{6,21}$. Recently, we were able to demonstrate that pulmonary shunt fraction is not elevated in COVID-19 patients compared to an ARDS cohort ${ }^{11}$. Increased ventilatory effort is thus rather the result of heavily increased $\mathrm{CO}_{2}$ production rather than right-to-left shunting. Almost all COVID-19 patients had high fevers, some as high as $40^{\circ} \mathrm{C}$, which might have contributed to $\mathrm{CO}_{2}$ accumulation. A recent retrospective analysis has connected fever of COVID-19 patients on admission to worse outcome ${ }^{22}$. Aggressive medical treatment of hyperthermia could limit respiratory drive and improve $\mathrm{CO}_{2}$ clearance in both awake and intubated patients.

Although simplifying a complex disease, the concept of L- and H-type COVID-19 introduced by Gattinoni et $\mathrm{al}^{23}$ reflects the observation that patients with COVID-19 tend to transition from sustained to impaired lung mechanics.

Early into the pandemic, intubation of COVID-19 patients was recommended permissively, mainly to prevent emergency intubation during acute deterioration and limit aerosol generation during non-invasive ventilation or high-flow oxygen supplementation ${ }^{24}$. This approach has been questioned by emerging insight into COVID-19 lung physiology 25 . The main advantages of invasive ventilation are maintenance of high positive end-exspiratory pressure and facilitating lung recruitment. If patients with early COVID-19 associated respiratory failure possess sustained lung mechanics, it appears questionable whether they benefit from early intubation, as derecruitment is probably not the leading cause of hypoxemia. This insight has raised the dilemma which COVID-19 patients should be mechanically ventilated, provided they do not require emergency intubation, and if so, when intubation should be performed.

Awake patients with COVID-19 pneumonia typically produce high tidal volumes with high negative intrathoracic pressures during non-invasive ventilation or high-flow nasal cannula ${ }^{26}$. The resulting mechanical strain puts them at risk of developing patient self-inflicted lung injury (pSILI), a concept which has already been described for other conditions with respiratory failure ${ }^{27}$. On the other hand, once patients are intubated, the need for $\mathrm{CO}_{2}$ control will most likely limit the possibilities of ventilating patients with tidal volumes low enough to limit ventilator-associated lung injury (VILI). Indeed, those COVID-19 patients from our cohort who did not receive veno-venous ECMO required higher tidal volumes and minute ventilation than what most physicians would consider 'protective' for ARDS. Furthermore, invasive ventilation increases the risk of ventilator-associated infections, possibly accelerating the transition from L- to H-type COVID-1925. This assumption is in line with our data which show that 
intubated COVID-19 patients without ECMO had required relatively high driving pressures throughout the course of disease. Interestingly, it is the ECMO group of COVID-19 patients in our cohort who had the heaviest losses in respiratory system compliance, possibly and paradoxically due to low driving pressures.

Our data suggest that reducing ventilation effort to a more protective scheme (e.g. 3-5 $\mathrm{ml} / \mathrm{kg}$ predicted body weight) in patients on ECMO might give way to a subsequent loss of respiratory system compliance. We assume that reduced alveolar gas exchange might lead to further alveolar derecruitment in these patients. Subsequent alveolar edema might finally lead to the condition Gattinoni and others have described as 'H-type' COVID-197. This effect was present even through, as outlined above, COVID-19 patients on ECMO had higher average PEEP than those without ECMO, suggesting that increase in PEEP alone is not sufficient to prevent derecruitment in these patients. While it is true that the danger of fatal hypoxia will probably be averted by ECMO, it is unknown whether this advantage can outweigh the longterm complications associated with derecruitment.

We did not detect a loss of compliance in our Influenza patients on ECMO, which is probably because respiratory system compliance was already severely impaired in these patients when they were intubated, hence protective ventilation on ECMO did not further jeopardize recruitment. As our mortality data shows, many COVID-19 patients do not recover from this state, questioning the role of highly protective ventilation on ECMO for COVID-19. A possible escape from this dilemma might be the initiation of awake ECMO in patients with L-type COVID-19. That way, vigorous respiratory effort could be limited easily through increased sweep gas flow, while avoiding invasive ventilation could reduce the risk of ventilatorassociated pneumonia. Obviously, the number of patients qualifying for this strategy will be limited, as cognition and compliance should be unimpaired to avoid accidental decannulation. Cohort data is required to assess the possible benefits of awake ECMO in patients with early COVID-19.

\section{Limitations}

Our study has several limitations that need to be addressed. First, as we present real-life data, matching of COVID-19 and control cohorts was not ideal, since COVID-19 patients were noticeably, yet not significantly, older compared to control. Secondly, being a tertiary care center, many patients were intubated in external hospitals and later transferred to our center for ECMO evaluation. Hence, data on the first days of ventilation is missing for some patients. As this is the case for both COVID-19 and Influenza patients, systematic error will probably be limited. Finally, given that COVID-19 is a relatively new disease and Influenza patients were recruited from the last ten years, we cannot exclude that changes in internal clinical standards and improved management of ARDS patients might account for systemic bias between groups.

\section{Conclusions}


The pathophysiology of early COVID-19-associated ARDS differs from Influenza-associated acute lung failure by sustained respiratory mechanics during the early phase of ventilation. Patients with early COVID-19-associated severe respiratory failure frequently exhibit sustained lung mechanics. In these patients, the benefit from early intubation seems questionable, as derecruitment is not the leading cause of hypoxemia. Replacing intubation by awake ECMO might be a way out of this situation.

\section{Abbreviations}

ARDS $\quad$ Acute respiratory distress syndrome

COVID-19 Coronavirus disease 2019

$\Delta \mathrm{P} \quad$ driving pressure

ECMO Extracorporeal membrane oxygenation

PEEP positive end-expiratory pressure

PP plateau pressure

RR Respiratory Rate

VILI Ventilator induced lung injury

VR Ventilatory ratio

\section{Declarations}

\section{Ethics approval and consent to participate}

Informed consent for the analysis of data is waived by the institutional review board due to the anonymous and retrospective analysis of data.

\section{Consent for Publication}

Not applicable.

\section{Availability of data and materials}

Data can be provided on request addressed to the corresponding author. All data sharing statements are subject to conformity with German data protection legislation and rules (Datenschutzgrundverordnung DGSVO).

\section{Conflict of interest disclosure}


Robert Bals declares funding from AstraZeneca, Boehringer Ingelheim,

GlaxoSmithKline, Grifols, Novartis, CLS Behring, the German Federal Ministry of Education and Research (BMBF) Competence Network Asthma and COPD (ASCONET), Sander-Stiftung, Schwiete-Stiftung, Krebshilfe and Mukoviszidose eV. Conflicts that the editors consider relevant to the content of the manuscript have been disclosed. All other authors: No potential conflicts of interest

\section{Financial funding}

COVID-19 research at the University Hospital of Saarland is funded by unrestricted grants of the Federal State of Saarland, Saarland University and Dr Rolf M. Schwiete Foundation. The funders had no role with regard to this study in the design of the study and collection, analysis, and interpretation of data or in writing the manuscript.

\section{Authorship Contribution}

P.L. and S.M. drafted the study. N.K. oversaw data collection and analysis. S.M. aided with statistical analysis and drafted the manuscript. F.S., G.D., R.M., C.R., A.B., M.K., T.R., C.M., R.B. and P.L. revised the manuscript for important intellectual content. All authors have seen and approved the final version of the manuscript.

\section{Acknowledgments}

NA

\section{References}

1. Hozhabri, Hossein; Piceci Sparascio, Francesca; Sohrabi, Hamidreza; Mousavifar, Leila; Roy, René; Scribano, Daniela et al. (2020) The Global Emergency of Novel Coronavirus (SARS-CoV-2): An Update of the Current Status and Forecasting. In : International journal of environmental research and public health, vol. 17, $n^{\circ} 16$. DOI: 10.3390/ijerph17165648

2. Raoult, Didier; Zumla, Alimuddin; Locatelli, Franco; Ippolito, Giuseppe; Kroemer, Guido (2020) Coronavirus infections: Epidemiological, clinical and immunological features and hypotheses. In : Cell stress, vol. 4, n 4, p. 66-75. DOI: 10.15698/cst2020.04.216

3. Gattinoni, Luciano; Coppola, Silvia; Cressoni, Massimo; Busana, Mattia; Rossi, Sandra; Chiumello, Davide (2020) COVID-19 Does Not Lead to a "Typical" Acute Respiratory Distress Syndrome. In : American journal of respiratory and critical care medicine, vol. 201, $n^{\circ} 10$, p. 1299-1300. DOI: 10.1164/rccm.202003-0817LE

4. Grieco, Domenico Luca; Bongiovanni, Filippo; Chen, Lu; Menga, Luca S.; Cutuli, Salvatore Lucio; Pintaudi, Gabriele et al. (2020) Respiratory physiology of COVID-19-induced respiratory failure compared to ARDS of other etiologies. In : Critical care (London, England), vol. 24, n 1, p. 529. DOI: $10.1186 /$ s13054-020-03253-2 
5. Gattinoni, Luciano; Chiumello, Davide; Rossi, Sandra (2020) COVID-19 pneumonia: ARDS or not? In : Critical care (London, England), vol. 24, n 1, p. 154. DOI: 10.1186/s13054-020-02880-z

6. Ferrando, Carlos; Suarez-Sipmann, Fernando; Mellado-Artigas, Ricard; Hernández, María; Gea, Alfredo; Arruti, Egoitz et al. (2020) Clinical features, ventilatory management, and outcome of ARDS caused by COVID-19 are similar to other causes of ARDS. In : Intensive care medicine, vol. 46, $n^{\circ} 12$, p. $2200-$ 2211. DOI: $10.1007 / \mathrm{s} 00134-020-06192-2$

7. Marini, John J.; Gattinoni, Luciano (2020) Management of COVID-19 Respiratory Distress. In : JAMA, vol. 323, n²2, p. 2329-2330. DOI: 10.1001/jama.2020.6825

8. Gattinoni, Luciano; Caironi, Pietro; Cressoni, Massimo; Chiumello, Davide; Ranieri, V. Marco; Quintel, Michael et al. (2006) Lung recruitment in patients with the acute respiratory distress syndrome. In : The New England journal of medicine, vol. 354, n 17, p. 1775-1786. DOI: 10.1056/NEJMoa052052

9. Dhont, Sebastiaan; Derom, Eric; van Braeckel, Eva; Depuydt, Pieter; Lambrecht, Bart N. (2020) The pathophysiology of 'happy' hypoxemia in COVID-19. In : Respiratory research, vol. 21, n 1, p. 198. DOI: 10.1186/s12931-020-01462-5

10. Santamarina, Mario G.; Boisier, Dominique; Contreras, Roberto; Baque, Martiniano; Volpacchio, Mariano; Beddings, Ignacio (2020) COVID-19: a hypothesis regarding the ventilation-perfusion mismatch. In : Critical care (London, England), vol. 24, n 1, p. 395. DOI: 10.1186/s13054-020-031259

11. Becker, André; Seiler, Frederik; Muellenbach, Ralf M.; Danziger, Guy; Kamphorst, Maren; Lotz, Christopher et al. (2021) Pulmonary Hemodynamics and Ventilation in Patients With COVID-19Related Respiratory Failure and ARDS. In : Journal of intensive care medicine, 885066621995386. DOI: $10.1177 / 0885066621995386$

12. Grieco, Domenico Luca; Bongiovanni, Filippo; Chen, Lu; Menga, Luca S.; Cutuli, Salvatore Lucio; Pintaudi, Gabriele et al. (2020) Respiratory physiology of COVID-19-induced respiratory failure compared to ARDS of other etiologies. In : Critical care (London, England), vol. 24, n 1, p. 529. DOI: 10.1186/s13054-020-03253-2

13. Li, Xu; Ma, Xiaochun (2020) Acute respiratory failure in COVID-19: is it "typical" ARDS? In : Critical care (London, England), vol. 24, n 1, p. 198. DOI: 10.1186/s13054-020-02911-9

14. Chiumello, Davide; Busana, Mattia; Coppola, Silvia; Romitti, Federica; Formenti, Paolo; Bonifazi, Matteo et al. (2020) Physiological and quantitative CT-scan characterization of COVID-19 and typical ARDS: a matched cohort study. In : Intensive care medicine, vol. 46, n 12, p. 2187-2196. DOI: 10.1007/s00134-020-06281-2

15. Mang, Sebastian; Kalenka, Armin; Broman, Lars Mikael; Supady, Alexander; Swol, Justyna; Danziger, Guy et al. (2021) Extracorporeal Life Support in COVID-19-related Acute Respiratory Distress Syndrome - a EuroELSO international survey. In : Artificial organs. DOI: 10.1111/aor.13940

16. Hong, Xiaoyang; Xiong, Jing; Feng, Zhichun; Shi, Yuan (2020) Extracorporeal membrane oxygenation (ECMO): does it have a role in the treatment of severe COVID-19? In : International journal of 
infectious diseases : IJID : official publication of the International Society for Infectious Diseases, vol. 94, p. 78-80. DOI: 10.1016/j.jijid.2020.03.058

17. Barbaro, Ryan P.; MacLaren, Graeme; Boonstra, Philip S.; Iwashyna, Theodore J.; Slutsky, Arthur S.; Fan, Eddy et al. (2020) Extracorporeal membrane oxygenation support in COVID-19: an international cohort study of the Extracorporeal Life Support Organization registry. In : The Lancet, vol. 396, $\mathrm{n}^{\circ}$ 10257, p. 1071-1078. DOI: 10.1016/S0140-6736(20)32008-0

18. Henry, Brandon Michael; Lippi, Giuseppe (2020) Poor survival with extracorporeal membrane oxygenation in acute respiratory distress syndrome (ARDS) due to coronavirus disease 2019 (COVID19): Pooled analysis of early reports. In : Journal of critical care, vol. 58, p. 27-28. DOI:

10.1016/j.jcrc.2020.03.011

19. Slutsky, Arthur S.; Ranieri, V. Marco (2013) Ventilator-induced lung injury. In : The New England journal of medicine, vol. 369, n²2, p. 2126-2136. DOI: 10.1056/NEJMra1208707

20. Gattinoni, L.; Tonetti, T.; Cressoni, M.; Cadringher, P.; Herrmann, P.; Moerer, O. et al. (2016) Ventilatorrelated causes of lung injury: the mechanical power. In : Intensive care medicine, vol. $42, n^{\circ} 10, p$. 1567-1575. DOI: 10.1007/s00134-016-4505-2

21. Haudebourg, Anne-Fleur; Perier, François; Tuffet, Samuel; Prost, Nicolas de; Razazi, Keyvan; Mekontso Dessap, Armand; Carteaux, Guillaume (2020) Respiratory Mechanics of COVID-19- versus NonCOVID-19-associated Acute Respiratory Distress Syndrome. In : American journal of respiratory and critical care medicine, vol. 202, n² 2, p. 287-290. DOI: 10.1164/rccm.202004-1226LE

22. Choron, Rachel L.; Butts, Christopher A.; Bargoud, Christopher; Krumrei, Nicole J.; Teichman, Amanda L.; Schroeder, Mary E. et al. (2021) Fever in the ICU: A Predictor of Mortality in Mechanically Ventilated COVID-19 Patients. In : Journal of intensive care medicine, vol. 36, n 4, p. 484-493. DOI: $10.1177 / 0885066620979622$

23. Gattinoni, Luciano; Chiumello, Davide; Caironi, Pietro; Busana, Mattia; Romitti, Federica; Brazzi, Luca; Camporota, Luigi (2020) COVID-19 pneumonia: different respiratory treatments for different phenotypes? In : Intensive care medicine, vol. 46, n 6, p. 1099-1102. DOI: 10.1007/s00134-02006033-2

24. Stawicki, Stanislaw P.; Jeanmonod, Rebecca; Miller, Andrew C.; Paladino, Lorenzo; Gaieski, David F.; Yaffee, Anna Q. et al. (2020) The 2019-2020 Novel Coronavirus (Severe Acute Respiratory Syndrome Coronavirus 2) Pandemic: A Joint American College of Academic International Medicine-World Academic Council of Emergency Medicine Multidisciplinary COVID-19 Working Group Consensus Paper. In : Journal of global infectious diseases, vol. 12, n² 2, p. 47-93. DOI: 10.4103/jgid.jgid_86_20

25. Rola, Philippe; Farkas, Joshua; Spiegel, Rory; Kyle-Sidell, Cameron; Weingart, Scott; Duggan, Laura et al. (2020) Rethinking the early intubation paradigm of COVID-19: time to change gears? In : Clinical and experimental emergency medicine, vol. 7, $\mathrm{n}^{\circ}$ 2, p. 78-80. DOI: 10.15441/ceem.20.043

26. Gattinoni, Luciano; Marini, John J.; Camporota, Luigi (2020) The Respiratory Drive: An Overlooked Tile of COVID-19 Pathophysiology. In : American journal of respiratory and critical care medicine, vol. 202, nº 8, p. 1079-1080. DOI: 10.1164/rccm.202008-3142ED 
27. Brochard, Laurent; Slutsky, Arthur; Pesenti, Antonio (2017) Mechanical Ventilation to Minimize Progression of Lung Injury in Acute Respiratory Failure. In : American journal of respiratory and critical care medicine, vol. 195, $n^{\circ}$ 4, p. 438-442. DOI: 10.1164/rccm.201605-1081CP

\section{Tables}

Table I - Basic patient data

$\operatorname{COVID}(n=25)$

$61,7[53,1-68,1]$

$20 / 5$

$1,77[1,73-1,81]$

$100,4[91,6-109,2]$

$32,3[29,0-35,5]$

$\left[\mathrm{kg} / \mathrm{m}^{2}\right]$

Comorbidities:
Adiposity (19)

Arterial Hypertension (13)

Diabetes mellitus Type II

(3)

Coronary Heart Disease (3)

Congestive Heart Failure

(3)

Past pulmonary embolism (3)

Past stroke (4)

Myasthenia gravis (1)
Influenza ( $\mathrm{n}=25)$

$55,7[45,5-65,4]$

$\mathrm{p}=$

$0.082^{\star}$

$16 / 9$

$1,73[1,70-1,76]$

$p=0.105$

$95,9[81,3-110,5]$

$p=0.573$

$31,5[27,0-36,0]$

$p=0.781$

Adiposity (10)

Arterial Hypertension (10)

Diabetes mellitus Type II

(9)

Coronary Heart Disease

(6)

COPD (4)

Chronic kidney disease

(3)

Epilepsy (2)

Atrial fibrillation

Cystic fibrosis

Asthma

*Mann-Whitney-U

Table II - Comparison of ventilation parameters on the first day of invasive ventilation 
COVID-19 Influenza A / B significance

\begin{tabular}{|c|c|c|}
\hline Arterial oxygen partial pressure [mmHg] & $\begin{array}{l}84.4[76.8- \\
92.1]\end{array}$ & $\begin{array}{l}93.3[71.8- \\
114.8]\end{array}$ \\
\hline & $\mathrm{n}=14$ & $\mathrm{n}=9$ \\
\hline
\end{tabular}

Inspiratory oxygen fraction during non-invasive ventilation / HFNC

$0.6[0.49-$

$0.70]$

$\mathrm{n}=14]$

Arterial carbon dioxide partial pressure [mmHg]

$\mathrm{pH}$

Horovitz-Index

$42.1[38.1-$ 46.0]

$\mathrm{n}=14$

$7.39[7.37-$

7.41]

$\mathrm{n}=14$

$127.9[112.8-$
$161.3]$

$N=14$

$12.0[9.6-$ 13.5]

$\left[\mathrm{cmH}_{2} \mathrm{O} / \mathrm{mbar}\right]$

Delta-P

Respiratory Rate* $\left[\mathrm{min}^{-1}\right]$
Plateau pressure $\left[\mathrm{cmH}_{2} \mathrm{O} / \mathrm{mbar}\right]$

$\left[\mathrm{cmH}_{2} \mathrm{O} / \mathrm{mbar}\right]$

Tidal volume [ml]

$\mathrm{N}=14$

$23.5[20.8-$ 29.0]

$\mathrm{N}=14$

$13.5[10.8-$ 16.0]

$\mathrm{N}=14$

$551[434.5-$
$593.8]$

$\mathrm{N}=14$

Tidal volume per $\mathrm{kg}$ predicted body weight [ml / $\mathrm{kg}]$
$7.69[7.12-$

8.12]

$\mathrm{N}=14$

$20.0[15.5-$

Page 16/20
$0.75[0.53-$

$0.84]$

$p=0.227$

$\mathrm{N}=9$

45.0 [38.1 -

$p=0.384$

51.9]

$\mathrm{n}=9$

$7.34[7.30-$

$p=0.03$

7.39]]

$\mathrm{N}=8$

$135.4[100.3-\quad p=0.557$
$180.4]$

$\mathrm{N}=9$

$13.0[9.0-$ $15.5]$

$p=0.369$

$\mathrm{N}=9$

$25.0[24.0-$ 28.5]

$p=0.561$

$\mathrm{N}=9$

$12.0[11.0-$ 14.5]

$p=0.643$

$\mathrm{N}=9$

431 [210 - 572] $\quad p=0.124$

$\mathrm{N}=9$

$5.12[3.14-$

$p=0.059$

8.40]

$\mathrm{N}=8$

$14.0[12.5-$

$p=0.011$ 


$\begin{array}{ll}21.3] & 17.5] \\ N=14 & N=9 \\ 10.7[7.2- & 6.0[2.5-10.1] \quad \mathbf{P = 0 . 0 1 3} \\ 12.2] & N=9 \\ N=14 & \end{array}$

* the real frequency of assisted spontaneous breathing was counted whenever intended and actual rates diverged by more than 2 per minute

Table III - Comparison of ventilatory system compliance and respiratory ratio on the first day of ventilation

COVID-19 Influenza A / B significance

$\begin{array}{llll}\text { Ventilatory system compliance [ml/mbar }] & 40.7[31.8- & 31.4[13.7- & P=0.198 \\ & 46.7] ; \mathrm{N}=14 & 42.8] ; \mathrm{N}=9 & \end{array}$

Ventilatory system compliance / kg idealized body weight [ml/mbar/ $/ \mathrm{kg}]$

$\begin{array}{lll}0.57[0.48- & 0.41[0.20- & P=0.150 \\ 0.70] ; N=14 & 0.59] ; N=8 & \end{array}$

Ventilatory Ratio

$1.57[1.31-$

1.84]; $\mathrm{N}=14$

$0.91[0.44-$

1.38]; $\mathrm{N}=7$

$P=0.006$

\section{Figures}



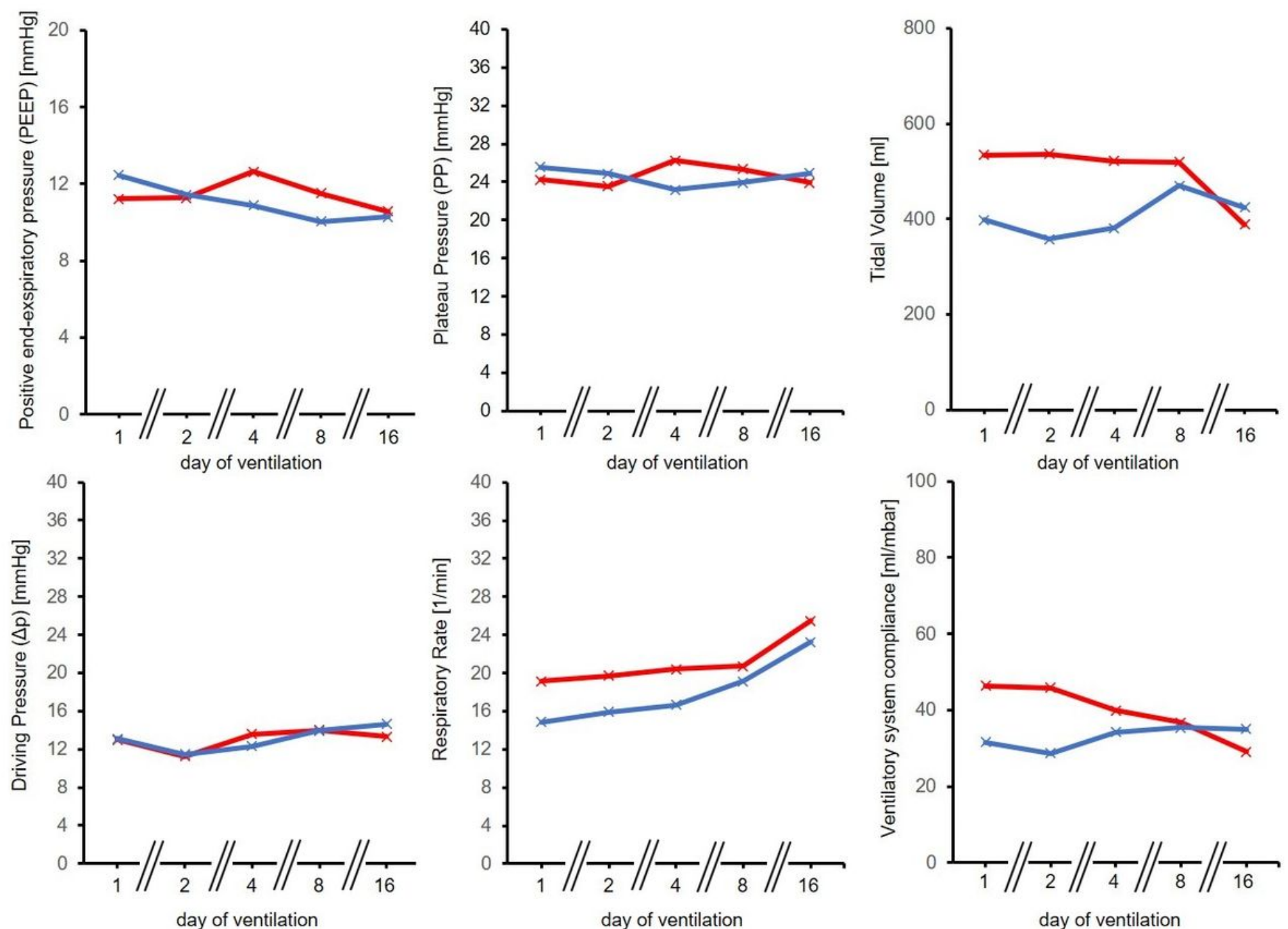

Figure 1

Development of ventilation parameters over time for COVID-19 and Influenza A / B Time course was similar in both groups for positive end-exspiratory pressure (PEEP), Plateau Pressure (PP) and Driving Pressure $(\Delta P)$. Respiratory Rate (RR), Tidal volumes and ventilatory system compliance were initially higher for the COVID-19 group. 


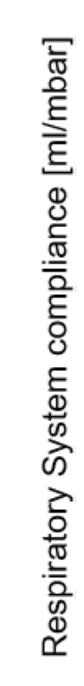

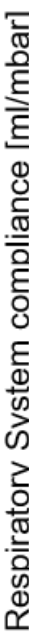
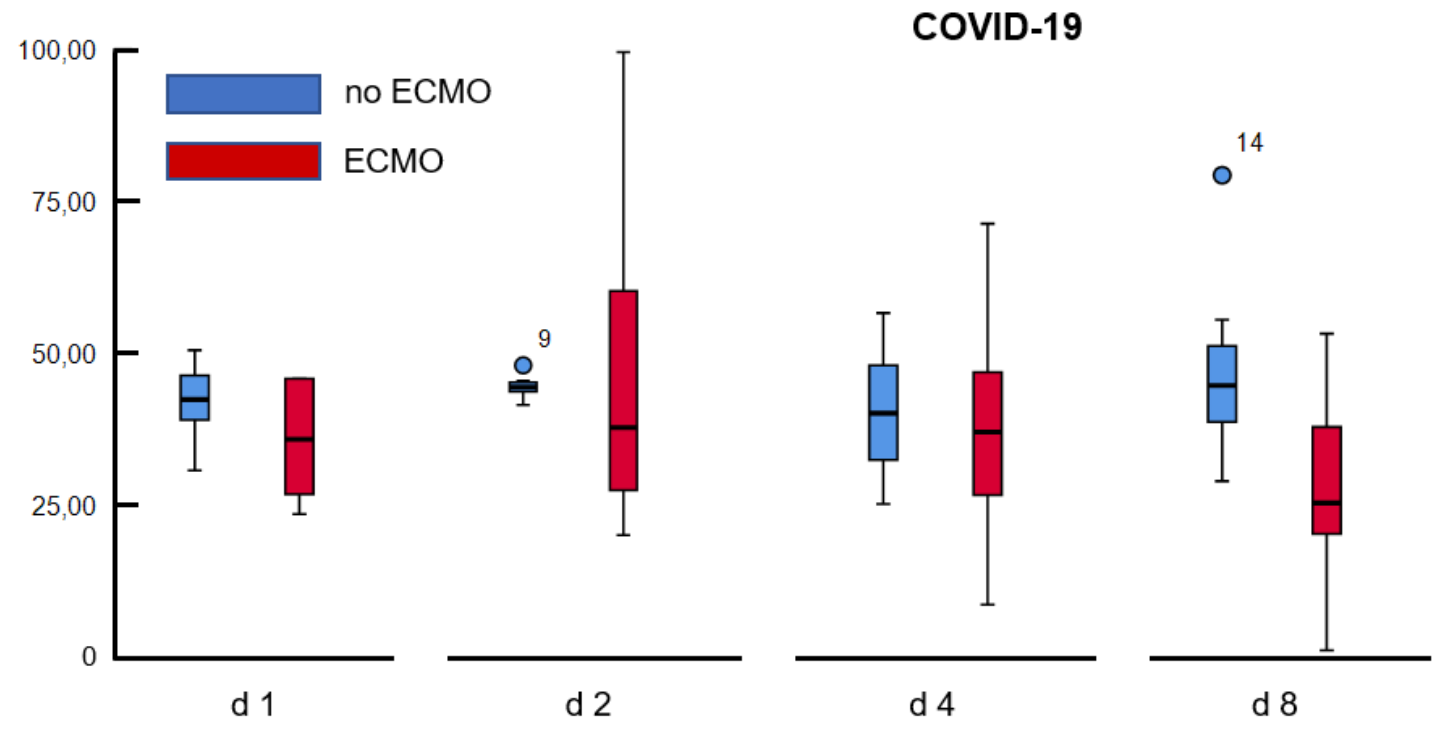

10

○

Influenza A / B
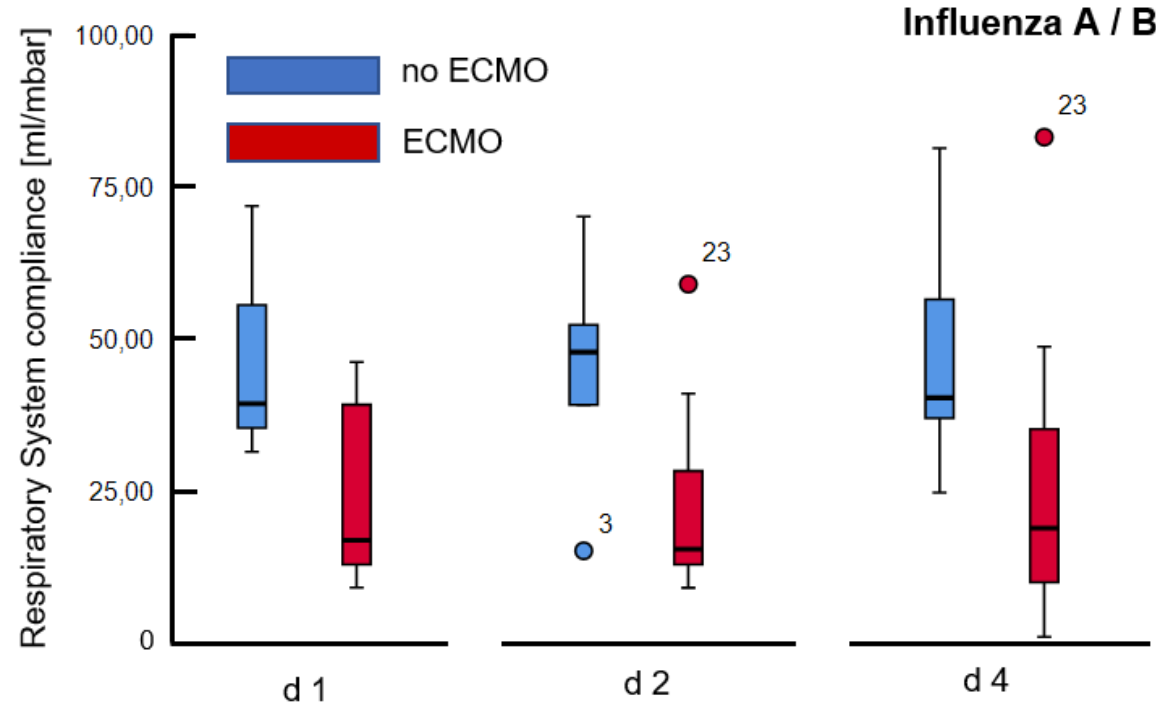

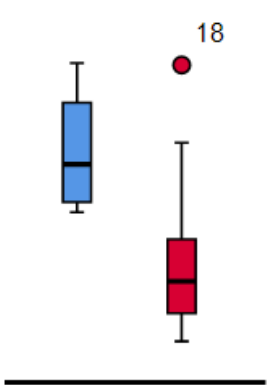

d 16

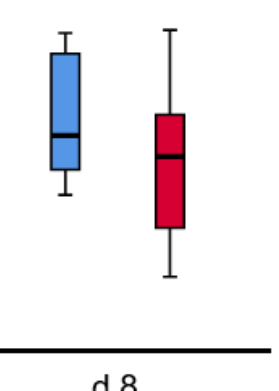

d 8

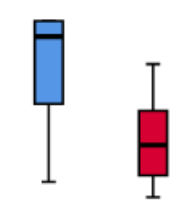

d 16

Figure 2

Development of Respiratory system compliance over time for COVID-19 and Influenza associated ARDS Histograms depict that ventilatory system compliance showed gradual decline over 2 weeks for COVID-19 patients on veno-venous ECMO, while compliance was severely impaired in Influenza patients from the very beginning of invasive ventilation, improving insigificantly over time. 


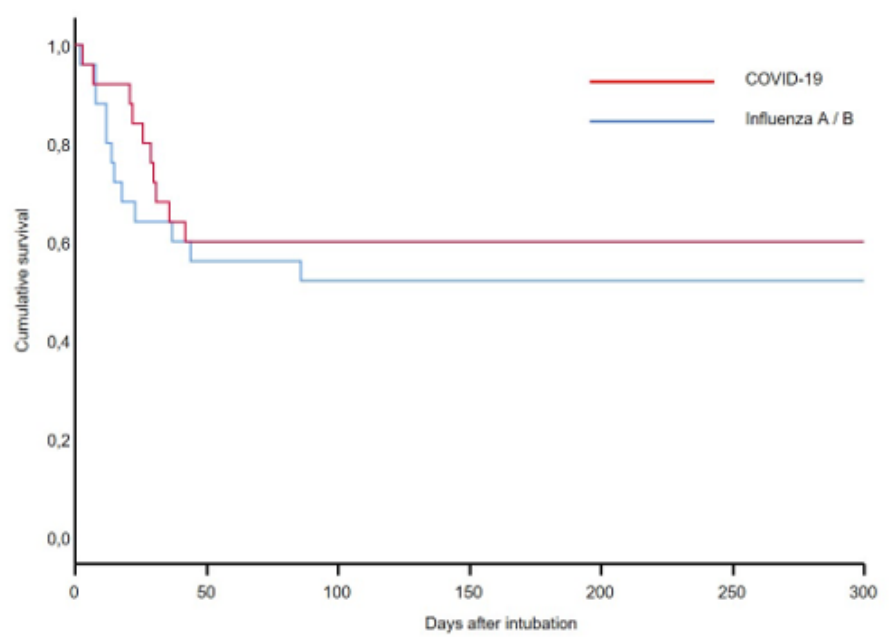

C)

B)
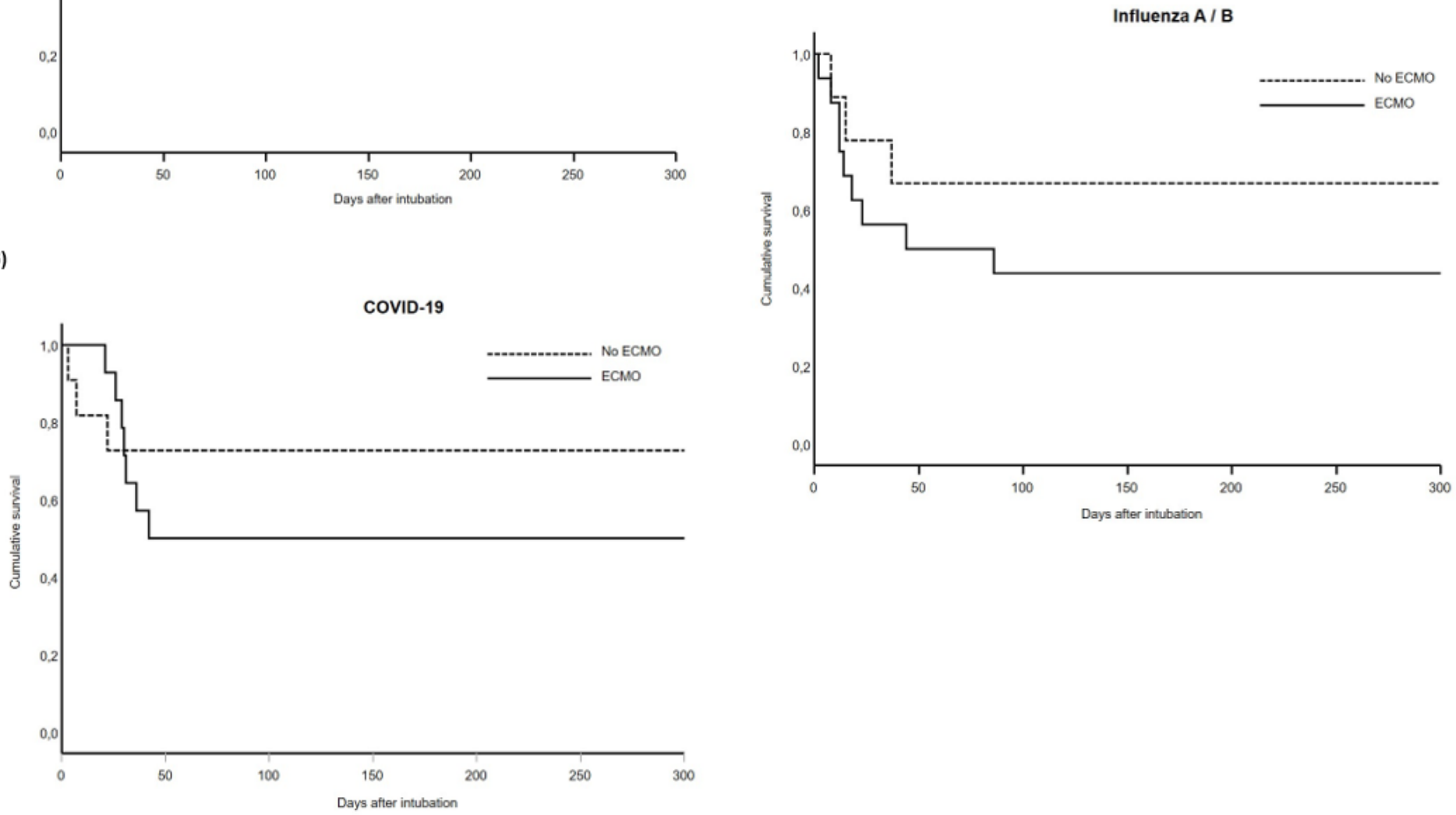

Figure 3

Kaplan-Meier-plots for COVID-19 and Influenza patients A) overall cumulative survival for COVID-19 and Influenza patients B) Subgroup analysis of cumulative survival for COVID-19 patients on ECMO and without ECMO C) Subgroup analysis of cumulative survival for Influenza patients on ECMO and without ECMO 